\title{
GUIDELINES FOR THE DESIGN, FABRICATION, TESTING, INSTALLATION AND OPERATION OF SRF CAVITIES
}

\author{
J. Theilacker, H. Carter, M. Foley, P. Hurh, A. Klebaner, K. Krempetz, \\ T. Nicol, D. Olis, T. Page, T. Peterson, P. Pfund, D. Pushka, R. Schmitt, \\ and R. Wands
}

Fermi National Accelerator Laboratory

Batavia, Illinois 60510, USA

\begin{abstract}
Superconducting Radio-Frequency (SRF) cavities containing cryogens under pressure pose a potential rupture hazard to equipment and personnel. Generally, pressure vessels fall within the scope of the ASME Boiler and Pressure Vessel Code however, the use of niobium as a material for the SRF cavities is beyond the applicability of the Code. Fermilab developed a guideline to ensure sound engineering practices governing the design, fabrication, testing, installation and operation of SRF cavities. The objective of the guideline is to reduce hazards and to achieve an equivalent level of safety afforded by the ASME Code. The guideline addresses concerns specific to SRF cavities in the areas of materials, design and analysis, welding and brazing, pressure relieving requirements, pressure testing and quality control.
\end{abstract}

KEYWORDS: Safety, Niobium, Pressure Vessel, SRF

\section{INTRODUCTION}

The use of superconductivity for high energy physics at Fermilab is evolving from superconducting magnets to superconducting RF cavities. Superconducting magnets have been used to steer or focus particle beams or to deflect charged particles in detectors. Superconducting RF cavities are used to accelerate charged particles. The next generation particle accelerator at Fermilab will likely utilize SRF cavities to accelerate protons, electrons or positrons in a linear accelerator.

Superconducting RF cavities are formed and welded from sheets of pure niobium into elliptical or spoke geometry. A helium containment vessel is then welded around the 
cavity. Figure 1 is an example of an elliptical cavity prior to welding of the helium containment vessel. Figure 2 is an example of a spoke cavity after welding of the helium containment vessel. From a pressure vessel standpoint, the helium containment vessel is internally pressurized, while the niobium cavity is externally pressurized.

At Fermilab, the helium containment vessel is typically made out of titanium grade 2 . For welding considerations, a transition section made out of a niobium/titanium alloy is used between the niobium cavity and the titanium helium containment. The use of niobium and a niobium/titanium alloy complicates pressure safety considerations since they are not recognized materials by ASME codes. Longer-term efforts are underway to develop a brazed or explosion bonded joint between niobium and stainless steel.

\section{PRESSURE SAFETY AT FERMILAB}

Pressurized system safety at Fermilab is governed by the Fermilab Environment, Safety and Health Manual (FESHM) [1]. Over the last three decades, chapters have been written to address a variety of pressurized systems, including cryogenic. Table 1 lists the FESHM chapters applicable to pressurized gas safety.

Pressure vessels are addressed by chapter 5031 which is based on the ASME Boiler and Pressure Vessel Code Section VIII (herein referred to as the Code) [2]. The chapter addresses vessels that are Code stamped, non-Code stamped vessels that are otherwise designed and built to Code, and vessels that do not meet Code requirements. Each pressure vessel requires a formal engineering note that is independently reviewed. Vessels that do not meet the Code require additional engineering justification and the Director's approval as an exception. Under the current rules of FESHM chapter 5031, every SRF cavity operated at Fermilab would require a Director's exception.

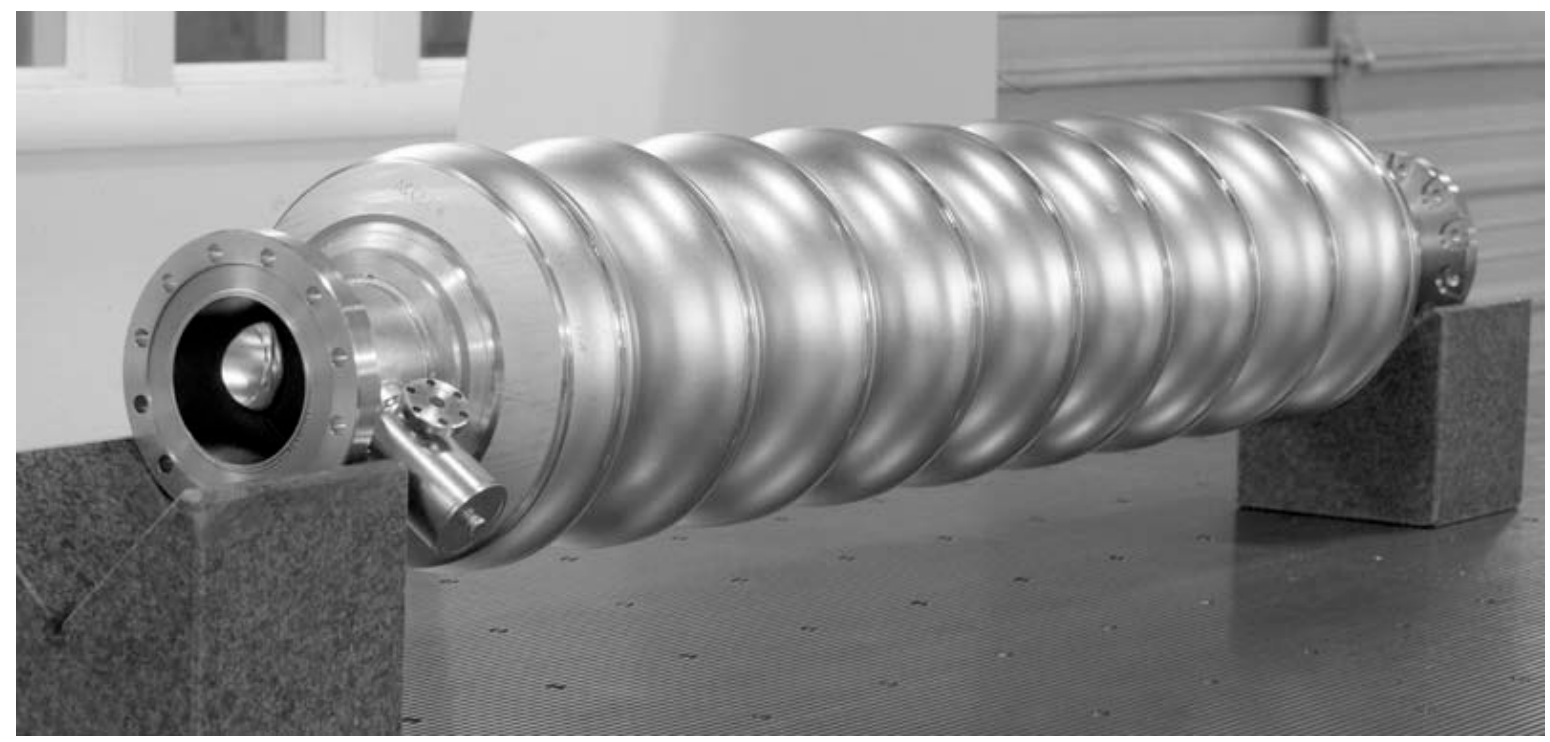

FIGURE 1. Elliptical nine cell niobium SRF cavity prior to installation of the surrounding helium containment vessel. 
Table 1. Fermilab Environment, Safety and Health Manual Chapters Associated with Pressure Safety.

\begin{tabular}{|l|l|l|}
\hline $\begin{array}{l}\text { FESHM } \\
\text { Chapter }\end{array}$ & Chapter Title & Comment \\
\hline 5031 & Pressure Vessels & Based on ASME Section VIII \\
\hline 5031.1 & Piping Systems & Based on ASME B31.3 \\
\hline 5031.2 & $\begin{array}{l}\text { Inert Gas Trailer Connections and Onsite Filling } \\
\text { Guidelines }\end{array}$ & $\begin{array}{l}\text { Unifies fittings and manifold } \\
\text { configurations }\end{array}$ \\
\hline 5031.3 & Gas Regulators & Unifies regulator inlet and outlet fittings \\
\hline 5031.4 & Inspection and Testing of Relief Systems & Based on ASME Section VIII \\
\hline 5031.5 & Low Pressure Vessels & $\begin{array}{l}\text { Based on ASME Section VIII for vessels } \\
\text { with large stored energy }\end{array}$ \\
\hline 5032 & Cryogenic System Review & $\begin{array}{l}\text { Establishes design, operating and safety } \\
\text { documentation requirements for new } \\
\text { cryogenic systems }\end{array}$ \\
\hline 5032.1 & $\begin{array}{l}\text { Liquid Nitrogen Dewar Installation and Operation } \\
\text { Rules }\end{array}$ & $\begin{array}{l}\text { Establishes valve and instrument } \\
\text { requirements, overfill protection, relieving } \\
\text { requirements and installation techniques }\end{array}$ \\
\hline 5032.2 & $\begin{array}{l}\text { Guidelines for the Design, Review and Approval } \\
\text { of Liquid Cryogenic Targets }\end{array}$ & $\begin{array}{l}\text { Guidelines for cryogenic targets used in } \\
\text { physics beamlines requiring minimum } \\
\text { beam impact }\end{array}$ \\
\hline 5032.3 & Transporting Gases in Building Elevators & Establishes uniform procedure \\
\hline 5033 & Vacuum Vessel Safety & $\begin{array}{l}\text { Based on ASME Section VIII for vessels } \\
\text { with large stored energy }\end{array}$ \\
\hline 5033.1 & Vacuum Window Safety & $\begin{array}{l}\text { Guidelines for vacuum windows in beam } \\
\text { transport pipes requiring minimum beam } \\
\text { impact }\end{array}$ \\
\hline 5034 & Pressure Vessel Testing & $\begin{array}{l}\text { Establishes testing procedures } \\
\text { procedure for Fermilab owned gas storage } \\
\text { cylinders }\end{array}$ \\
\hline 5034.1 & $\begin{array}{l}\text { Retesting Procedures for D.O.T. Gas Storage } \\
\text { Cylinders Including Tube Trailers }\end{array}$ & Based on ANSI/ASHRAE 15 \\
\hline 5035 & Mechanical Refrigeration Systems & anding \\
\hline
\end{tabular}

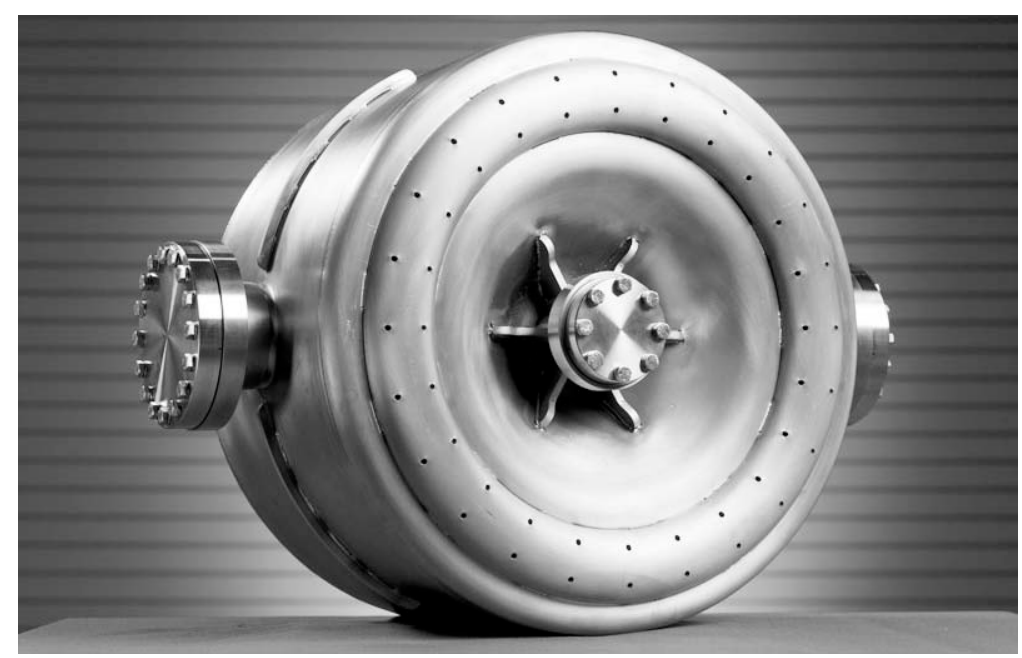

FIGURE 2. Spoke niobium SRF cavity after installation of the surrounding helium containment vessel. 
The U.S. Department of Energy also addresses pressure safety for all activities under its jurisdiction in Worker Safety and Health Program, 10CFR851 [3]. The basis of this program is the ASME pressure vessel and piping codes. However, the program recognizes that R\&D within DOE sometimes requires devices which are beyond the applicability of the ASME codes. It states that "When national consensus codes are not applicable (because of pressure range, vessel geometry, use of special materials, etc.), contractors must implement measures to provide equivalent protection and ensure a level of safety greater than or equal to the level of protection afforded by the ASME or applicable state or local code." The program goes on to describe control measures for ensuring equivalent protection. The measures include a technical design review and approval by a qualified independent professional, examination and inspection by a qualified person, and document control.

Material properties alone make it impossible to design and manufacture SRF cavities to the Code. Other aspects, such as geometry and weld types, can be designed to the Code, but not without considerable difficulty in the design and testing phases. In addition, relieving requirements for SRF cavity based systems has special considerations, which must be properly addressed. As a result, a committee was formed in 2008 to develop guidelines for the design, fabrication, testing, and installation of SRF cavities at Fermilab. The intent of the guidelines is to ensure a design that is consistent with the intent of the Code as well as 10CFR851 without the need for requiring a Director's exception. In addition, the guidelines will provide a framework that will help to ensure that SRF cavity engineering notes are reviewed in a consistent manner.

\section{NEW SRF CAVITY GUIDELINES}

A new chapter of the FESHM has been developed and is currently under review, titled Guidelines for the Design, Fabrication, Testing and Installation of SRF Nb Cavities. The use of a guideline to control the uniformity and quality of a system design and review is not new to Fermilab. FESHM chapter 5032.2, Guidelines for the Design, Review and Approval of Liquid Cryogenic Targets was developed to address similar concerns in liquid cryogenic targets. Both of these chapters are sub chapters under Cryogenic System Review, 5032, since they also involved installation requirements.

The SRF cavity guideline has chapters to address materials, design and analysis, welding and brazing, pressure relief requirements, pressure testing, and quality control. Highlights from each chapter of the guideline are described below.

\section{Materials}

Since niobium and niobium alloys are not Code materials, this section of the guideline describes the material testing requirements in order to carry out a design consistent with the intent of the Code. The required testing includes yield strength, ultimate strength, Young's modulus, and Charpy impact energy. In addition, the chemical composition of the sample is determined. Testing is conducted at room temperature, $77 \mathrm{~K}$, and $4.5 \mathrm{~K}$. A minimum of three samples are required in both the longitudinal and transverse directions for bulk material and welded or brazed material specimens.

The yield and ultimate strength results are used to determine the allowable stress in accordance with Section II, Part D, Mandatory Appendix 1 of the Code. In addition, the Young's modulus is required to properly analyze externally pressurized vessels, such as SRF cavities. 


\section{Design and Analysis}

This section of the guideline outlines the Code design and analysis requirements that need to be considered when designing SRF cavities. To aid the designer, two appendices are included; one giving an overview of the Code in the context of SRF cavity design and one showing how to apply Div. 1 rules to an elliptical and spoke cavity design.

The cavity designer must first choose whether the design and analysis is carried out in accordance to Division 1 or Division 2 of the Code. In order to use Div. 1 for the vessel design and construction, the provisions of paragraph U-2(g) must be incorporated. Rules for the stress analysis of vessels are given in Div. 2, Part 5 of the Code. The application of Part 5 rules does not imply a Div. 2 design; the techniques are a sound approach to the analysis of any pressure vessel. However, if Div. 1 is used, then allowable material properties and joint efficiencies consistent with Div. 1 must be used.

This section goes on to describe the pros and cons of elastic versus elastic-plastic analysis techniques. Two appendices are included which give an overview of the Code in the context of SRF cavities and the application of Div. 1 rules to elliptical and spoke SRF cavities.

\section{Welding and Brazing}

The Code welding and brazing rules that are of particular interest in the design of SRF cavities are presented in this section. An appendix is provided to give guidance on the development of a weld procedure specification (WPS) for electron beam and TIG welds based on sample examination using microscopic or scanning electron microscope techniques for procedure verification.

Welding titanium or its alloys to other materials is prohibited by Div. 1, but not by Div. 2. This complicates the use of Div. 1 for any SRF cavity which uses titanium helium containment.

In order to help maintain a uniform and clean surface, SRF cavities are welded using electron beam welding machines. The Code requires $100 \%$ ultrasonic inspection of electron beam welds. It is not uncommon to have the geometry of end joints within a SRF cavity that are impractical to test ultrasonically.

Div. 1 requires that if geometric details are given for a particular joint configuration, then those details must be used in the vessel. There are also several details which are explicitly prohibited. Historically, non-Code welds have been a major impediment to the Code qualification of cavities. Therefore, it should be emphasized that qualification of the cavity under Div. 1 rules requires that special attention be given to following all requirements of Part UW (welding) and UB (brazing) with regard to joint configuration and weld type.

\section{Pressure Relief Requirements}

Pressure relieving requirements that need to be applied to SRF cavities are discussed in this section of the guideline. The requirements are based on the Code as well as the Compressed Gas Association (CGA) Pressure Relief Device Standards CGA S-1.3 [4].

SRF cavities typically have a large surface area between the beam tube volume and the liquid helium volume. This presents a particularly demanding relieving requirement in the event of a large air in-leak to the beam vacuum volume. Under this failure mode, air rushes in at sonic velocity and freezes out on the niobium. This results in film boiling of 
the helium with a large temperature difference. The resulting heat flux has been measured by Lehmann and Zahn to be up to $4 \mathrm{~W} / \mathrm{cm}^{2}$ [5]. Considerations must also be given to the loss of cryostat vacuum. The surface area on the outside of the helium containment and the effects of any multilayer insulation and/or magnetic shielding material must be taken into account.

\section{Pressure Testing}

In the previous section it was shown that the most stringent relieving requirement requires $\mathrm{LHe}$ to be present in the helium containment vessel. This raises interest in the concept of having a dual maximum allowable working pressure (MAWP) for SRF cavities. The MAWP at LHe temperature, where the allowable stress in niobium is considerably higher than room temperature, would be higher in order to better accommodate the relieving requirements. Above LHe temperature, the MAWP would be based on room temperature material properties and relieving requirements handled by a smaller lower pressure operational relief valve.

For materials that have higher allowable stresses at cryogenic temperatures, UG100(b) provides a means for pressure testing at room temperature at a lower pressure. This provision can be used to avoid the use of a dual MAWP, but not without design implications. Some helium containment vessels are made out of titanium which is a Code material that does not have recognized property improvement at cryogenic temperatures. As a result, in order to avoid the dual MAWP and associated dual pressure test, the helium containment vessel would have to be overdesigned.

\section{Quality Control}

Implementation of proper quality control applied to SRF cavities is an important means for satisfying the requirements of 10CFR851. In this section of the guidelines, the Code quality control requirements specific to SRF cavities are examined as related to inspections and the quality control system used in the design, fabrication and testing phases.

The inspector used must be certified by the controlling jurisdiction (usually the state uses the National Board commissioning system). If the manufacturer is the end user, then the certified inspector can be an employee of the manufacturer.

Both Div. 1 and Div. 2 include an outline of features for the quality control system. A list of these topics, with commentary specific to SRF cavities where applicable, is given below.

\section{Authority and Responsibility \\ 2. Organization}

3. Drawings, Design Calculations, and Specifications - It should be noted that the Inspector does not check the calculations or specifications, but only ensures that they exist and are in accordance with the specific requirements for the vessel in question.

4. Material Control - The SRF cavities will use materials which are not approved by the Code. Procedures for materials property testing, determination of allowable stresses, and documentation requirements are presented in the Materials section of this Guideline. Material tracking and certification are a large part of the Quality Assurance program and subject to Inspection.

5. Examination and Inspection - The designer must determine what inspections and examinations are required. For those components not meeting The Code 
requirements due to disqualifying features, alternatives must be developed that provide an equivalent level of safety. For example, in the case of welding examinations, an alternative approach may be to perform sufficient examinations of sample welds to qualify production welds (such as semi-automated electron beam welding). Note that Div. 1 allows exception from all inspection requirements if full radiography is not required and certain pressure and volume values are not exceeded (U-1(c)(2)(g), UM stamp). Div. 2 does not allow this exception. Also note that radiography is not required in Div. 1 for those welds that assume low enough weld efficiency in the design.

6. Correction of Nonconformities - The quality control system shall define a system to correct nonconformities that arise during manufacture. The Inspector has to agree to this system. For some nonconformity, the Code includes requirements for corrections, otherwise it relies on the Inspector's judgment.

7. Welding and Brazing - Welder performance needs to be captured in the quality control system (through the usual WPS, PQR, WQR's, etc.) as well as examination results. One must make sure that welding materials are also tracked and certified as the other material controls.

8. NDE

9. Heat Treatment

10. Calibration of Measurement and Test Equipment

11. Records Retention - Div. 1 lists record retention requirements in Appendix 10 and generally is 3 years for all documents needed to show compliance to the Code. For UM stamped vessels the requirement is reduced to 1 year. Div. 2 lists record retention requirements in a separate Annex, 2.C Report Forms and Maintenance of Records. These record requirements are more specific and include as-built drawings and results of production test plates. Retention time is still 3 years.

12. Inspection of Vessels and Vessel Parts - Previously described.

13. Inspection of Pressure Relief Valves - This only applies to manufacturers of pressure relief valves.

\section{CONCLUSIONS}

Guidelines have been developed at Fermilab for the design, fabrication, testing and installation of niobium based SRF cavities. The guidelines will become a formal chapter of the Fermilab Environment, Safety and Health Manual. The purpose of the guidelines is to ensure consistent design and review of SRF cavities that will meet the requirements of the U.S. DOE Worker Safety and Health Program, 10CFR851.

\section{ACKNOWLEDGEMENTS}

This work is supported by Fermi Research Alliance, LLC, under contract No. DEAC02-07CH11359 with the U. S. Department of Energy.

\section{REFERENCES}

1. Fermi National Accelerator Laboratory, Fermilab Environment, Safety \& Health Manual, http://wwwesh.fnal.gov/pls/default/esh_home_page.page?this_page=800. 
2. American Society of Mechanical Engineers, ASME Boiler \& Pressure Vessel Code, ASME, New York, 2007.

3. U. S. Department of Energy, Title 10, Code of Federal Regulations, Part 851, Worker Safety and Health Program, http://www.hss.energy.gov/HealthSafety/WSHP/rule851/851preamble.pdf.

4. Compressed Gas Association, Inc., Pressure Relief Device Standards Part 3 - Stationary Storage Containers for Compressed Gases, Eighth Edition, Chantilly, Virginia, 2008.

5. Lehmann, W. and Zahn, G., "Safety Aspects for LHe Cryostats and LHe Transport Containers," Proceedings of the Seventh International Cryogenic Engineering Conference, IPC Science \& Technology Press, 1978, pp. 569-579.

6. Cavallari, G., Gorine, I., Güsewell, D. and Stierlin, R., "Pressure Protection Against Vacuum Failures on the Cryostats for LEP SC Cavities, " CERN internal note AT-CR/90-02 presented to the 4th Workshop on RF Superconductivity, Tsukuba, Japan, 1989.

7. Wiseman, M., Crawford, K., Drury, M., Jordan, K., Preble, J., Saulter, Q., and Schneider, W., "Loss of Cavity Vacuum Experiment at CEBAF,“ Advances in Cryogenic Engineering - 39, Plenum Press New , Plenum Press New York, 1994, pp. 997-1003. 